\title{
NeuroRehab
}

News

\section{Beneficios del Ejercicio Físico sobre la Neuroplasticidad y la Cognición}

Neuroplasticidad y ejercicio

\section{Resumen:}

\begin{abstract}
a neuroplasticidad es la capacidad que tiene el cerebro de adaptarse a las demandas cambiantes alterandolas propiedadesfuncionalesyestructurales, dandolugaralaprendizajey laadquisición de habilidades. Estudios realizados en animales y humanos han demostrado que la actividad física facilita la neuroplasticidad en ciertas estructuras cerebrales, y como resultado, en funciones cognitivas. Las funciones cognitivas son los procesos mentales que nos permiten entender y relacionarnos con el mundo que nos rodea a través de la obtención, almacenamiento y transformación de toda la información que recibimos del exterior. En este artículo analizaremos y estudiaremos los beneficios neurocognitivos del ejercicio físico y sus consecuencias en las estructuras cerebrales.
\end{abstract}

Los precursores que plantearon la idea de que el sistema nervioso central podía cambiar y no era limitado fueron William James y Ramon y Cajal, aunque no fue hasta los años 60 cuando se realizaron los primeros estudios. Ahora se sabe a ciencia cierta que el cerebro está en continuo cambio debido a la información que recibimos constantemente del medio exterior, llamándose a este proceso neuroplasticidad

Es bien conocido por todos los efectos beneficiosos que posee el ejercicio físico en nuestras vidas, pero ¿qué efecto tiene en nuestro cerebro y las funciones cognitivas?

Para conocer el efecto que la actividad física produce en nuestro cerebro a nivel cognitivo y estructural, el primer paso necesario es estudiar todos los procesos químicos y neurobiológicos que se desencadenan al realizar algún deporte.

La producción del factor neurotrófico cerebral (BDNF) se ve aumentada cuando practicamos ejercicio físico. Las neurotrofinas son una familia de proteínas, siendo una de sus funciones principales impedir a las neuronas diana que inicien la muerte celular programada (apoptosis), es decir, permitiendo así que las neuronas sobrevivan promoviendo por tanto el desarrollo de neuronas inmaduras y la supervivencia de las adultas.

Este desarrollo está claramente relacionado con lo que se conoce como potenciación a largo plazo gracias a la cual nuestro cerebro puede realizar nuevos aprendizajes, adquirir nuevas habilidades y generar neuroplasticidad.

A través del avance de la ciencia, y gracias a las nuevas tecnologías en imágenes cerebrales, se ha conseguido demostrar cómo la adquisición de estas nuevas habilidades o aprendizajes pueden llegar a cambiar la estructura neuronal. En algunas ocasiones, este cambio o plasticidad puede provocar una desadaptación o dolor. La producción del factor neurotrófico cerebral BDNF se localiza en mayor medida en el hipocampo y la zona frontal de la corteza cerebral, lo que hace que sea un factor sumamente importante para el aprendizaje, la memoria y el desarrollo de habilidades.

Está demostrado que no todos los tipos de ejercicios tienen las mismas consecuencias, afectando de forma diferente a distintas estructuras neuronales de nuestro cerebro. Por lo tanto, podemos asumir que no solamente el ejercicio aeróbico es importante, sino que el ejercicio anaeróbico posee también gran importancia potenciando funciones como la ejecutiva. La función ejecutiva, entre otras muchas cosas, es la encargada de la capacidad de planificación, organización y gestión del tiempo, entre otras habilidades. Así mismo otros factores, como las relaciones sociales, pueden influir

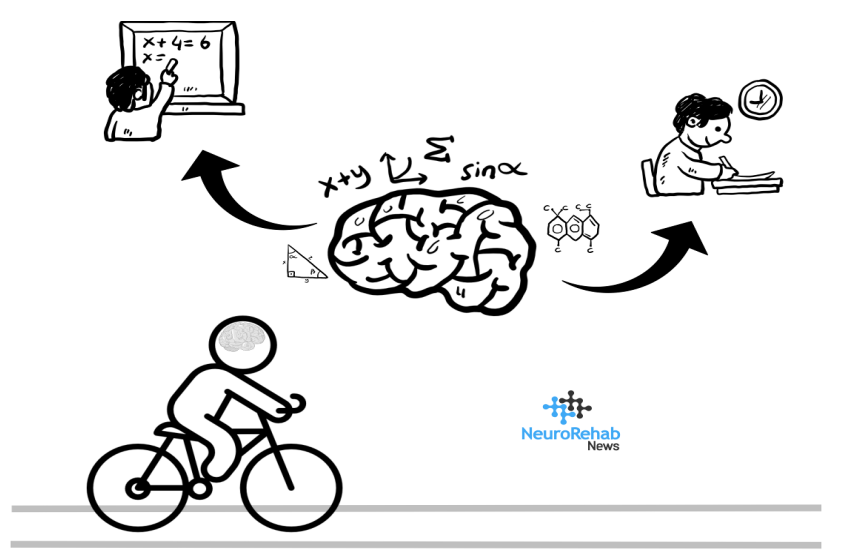


de la misma manera en la cognición y la memoria.

Existe una relación muy grande, demostrada por estudios recientes, entre la práctica de ejercicio físico y un alto rendimiento en test neuropsicológicos, que miden aspectos como la percepción motriz, la creatividad y la concentración. Las personas físicamente activas presentan una media mucho más elevada en rendimiento académico con unas mayores facilidades de adquirir habilidades. La plasticidad neuronal presenta una mayor importancia en la adolescencia, siendo más fácil la adaptación de las estructuras neuronales a esta edad. Además, la actividad física también previene del deterioro cognitivo en edades más avanzadas.

Por lo tanto, las personas que realizan una actividad física constante a lo largo del tiempo mostraron mayores habilidades de razonamiento abstracto, memoria de trabajo, flexibilidad cognitiva y planeación estratégica.

Los beneficios de la actividad física pueden ser utilizados con fines sanitarios para personas con enfermedades neurodegenerativas y para el mantenimiento de sus capacidades cognitivas.

\section{"Las funciones ejecutivas son las encargadas de la capaci- dad de planificación, organ- ización y gestión del tiempo, entre otras habilidades"}

\section{Conclusión:}

El ejercicio físico, aparte de sus beneficios en el bienestar general y la vida cotidiana, tiene un papel muy importante en la mejora de procesos cognitivos y plasticidad neuronal, así como en la prevención del deterioro cognitivo.

\section{Sobre este artículo:}

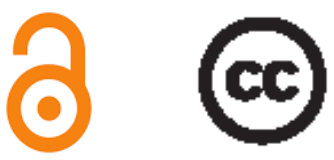

\section{Fuente /s:}

Hötting K, Röder B. Beneficial effects of physical exercise on neuroplasticity and cognition. Neurosci Biobehav Rev. 2013; 37: 2243-57.

Fuente de la Imagen: imagen de NeuroRehabnews.com con fines unicamente ilustrativos.

Autora: Cristina Sáenz Jiménez

Para citar este artículo: Sáenz-Jiménez C. Beneficios del Ejercicio Físico sobre la Neuroplasticidad y la Cognición. NeuroRehab News 2017 nov; 2 (1): e0031

Cristina

Sáenz

Jiménez 